\title{
Milk - An Effective Low-Attenuation Computed Tomography Oral Contrast Medium
}

\author{
Sharmin Akhtar Rupa ${ }^{1}$, Salahuddin Al Azad ${ }^{2}$, Nehar Ranjan Chakraborty ${ }^{3}$
}

\begin{abstract}
Background: To evaluate gastrointestinal pathology in computed tomography (CT) scan, optimum distention, mural visualization and gastrointestinal tract discrimination are necessary. High attenuation oral contrast material in the form of iodine solution has drawbacks in mural visualization and tolerance. Milk can be used as a low attenuation CT oral contrast agent in gastrointestinal tract discrimination and mural visualization with better tolerance. Objective: The purpose of our study was to compare the effectiveness, cost, and tolerance of milk and iopamiro (iodinated positive contrast medium) in patients undergoing abdominal CT with oral and IV contrast media. Materials and Methods: Two hundred and twelve patients were purposively assigned to receive either whole milk $(n=110)$ or iopamiro $(n=100)$. Results were independently reviewed by radiologists. Degree of bowel distention, mural visualization and gastrointestinal tract discrimination were qualitatively scored on a 4point scale. A questionnaire regarding oral contrast tolerability was provided to each patient. Cost comparison of the two agents was performed. Results: No statistically significant differences were seen between whole milk and iopamiro with respect to degree of bowel distention and gastrointestinal tract discrimination for all segments of bowel studied $(p>0.05)$. Mural visualization is better with whole milk compared with iopamiro $(p<0.05)$. Significantly more patients ranked milk as pleasant in taste compared with iopamiro $(p<0.05)$. Milk was better tolerated than iopamiro, with fewer gastrointestinal side effects, including abdominal discomfort $(p=0.065)$, cramping $(p=0.309)$, nausea $(p=0.001)$, vomiting $(p=0.003)$ and diarrhea $(p=0.347)$. The cost per patient for iopamiro is 900 BDT compared with 60 BDT for milk. Conclusion: Whole milk is comparable to iopamiro with respect to bowel distention and gastrointestinal tract discrimination and better in bowel wall visualization and has better patient acceptance, and fewer adverse symptoms. Milk is a costeffective alternative to iopamiro as a low-attenuation CT oral contrast agent.
\end{abstract}

Key words: Milk, Iopamiro, CT scan, Optimum distention, Mural visualization, Gastrointestinal tract discrimination

J Enam Med Col 2013; 3(2): 71-76

\section{Introduction}

Evaluation of gastrointestinal pathology depends on adequate bowel distention, which optimizes resolution of the bowel wall and contents. Traditionally, high-attenuation oral contrast material in the form of iodine solutions has been used to

obtain bowel distention. ${ }^{1-4}$ However, because of drawbacks such as poor mural discrimination and interference with 2D and 3D multiplanar reformations ${ }^{5}$, low-attenuation oral contrast material has been sought.

1. Associate Professor, Department of Radiology \& Imaging, Enam Medical College \& Hospital, Savar, Dhaka

2. Professor, Department of Radiology \& Imaging, Bangabandhu Sheikh Mujib Medical University, Dhaka

3. Junior Consultant, Department of Radiology \& Imaging, Central Hospital Limited, Dhaka

Correspondence Sharmin Akhtar Rupa,Email: dr.sharminakhtarrupa@yahoo.com 
Multiple low-attenuation oral contrast agents have been studied. ${ }^{5-11}$ Although air had been advocated as an alternative to high-attenuation oral contrast material for gastric and large-bowel imaging ${ }^{12}$, the production of artifacts and the requirement of wide window settings for viewing render it a suboptimal agent for soft-tissue contrast resolution. ${ }^{13}$ Taking advantage of the inherent contrast between water attenuation and contrast material-enhanced bowel wall, Winter et $\mathrm{al}^{6}$ used water as an oral contrast agent, resulting in excellent luminal and mucosal depiction of the upper gastrointestinal tract. However, the use of water requires the additional use of an upper gastrointestinal smooth muscle relaxant and does not provide adequate evaluation of the distal small bowel. Previous investigations of fatcontaining oral contrast agents such as one comprising $12.5 \%$ corn oil showed excellent gastrointestinal tract discrimination and mural visualization without a significant difference in patient tolerance as compared with barium suspension and iodine solutions. ${ }^{7}$ However, such agents either are not commercially available or are fat-containing food supplements that are expensive. In addition, metoclopramide hydrochloride was required to promote gastrointestinal peristalsis inhibited by the high fat content. Moreover, such high fat content is often unacceptable to patients. Although polyethylene glycol (PEG) provides better small-bowel distention and reaches the colon more readily than a full-strength fiber mixture and water ${ }^{14}$, the high cost per examination and patients' dissatisfaction with this unpalatable mixture and its abdominal side effects such as diarrhea prevented the widespread adoption of PEG preparations.

Whole milk (4\%) has been shown to be costeffective. The fat contained in whole milk effectively slows upper gastrointestinal tract motility, obviating the use of either smooth muscle relaxants or metoclopramide hydrochloride. Whole milk provides superior mural visualization and discrimination of the pancreas and duodenum compared with bariumbased contrast material and water. In addition, gastrointestinal tract distention and small-bowel discrimination were comparable to those in studies using a barium suspension and superior to imaging performed with water. $^{5}$ More recently, a newly developed low-attenuation $0.1 \%$ barium suspension (Volumen, E-Z-EM Inc.) has been shown to provide excellent gastrointestinal tract distention and superb visualization of mural features compared with barium suspension and a methylcellulose-water mixture. ${ }^{12}$

We hypothesize that milk will be well tolerated, more cost-effective, better than iopamiro for mural visualization with similar degrees of gastrointestinal tract distention and discrimination as iopamiro.

\section{Materials and Methods}

This study was carried out in Radiology and Imaging Department of Bangabandhu Sheikh Mujib Medical University, Dhaka from January to December 2009. Two hundred and ten outpatients referred for both oral and IV contrast-enhanced abdominal CT were purposively assigned to receive either whole milk or iopamiro (iodinated positive contrast medium). No flavoring material was added to the whole milk. Patients with history of lactose intolerance, allergy to iodinated contrast material and gastric surgery and serum creatinine greater than $1.5 \mathrm{mg} / \mathrm{dL}$ were excluded from the study. All patients enrolled in the study were informed of purpose of the study and consent was taken.

One hundred patients received $1000 \mathrm{~mL}$ of water mixed with iopamiro $(40 \mathrm{~mL})$ and 110 patients received $1000 \mathrm{~mL}$ of whole milk divided into four doses $(250 \mathrm{~mL} 45$ minutes before scanning, $250 \mathrm{~mL}$ 30 minutes, $250 \mathrm{~mL} 15$ minutes and $250 \mathrm{~mL}$ immediately before scanning).

CT examinations of all study subjects were performed using a single slice spiral CT scanner (Hitachi) creating 10-mm sections. All examinations were performed using IV contrast material (Iopamiro, 300). Neither IV glucagon nor metoclopramide hydrochloride was administered.

The studies were qualitatively evaluated independently by radiologists for luminal distention of the duodenum, jejunum, and ileum, which was graded on a scale of $0-3$, with 0 being no distention, 1 being minimal $(1 \mathrm{~cm})$ distention, 2 being good partial $(1-2 \mathrm{~cm})$ distention, and 3 being excellent $(>2 \mathrm{~cm})$ distention. Evaluation of the antrum was based on a similar qualitative grading scale of $0-3$ 
without specific measurements. Non uniform duodenal distention was frequently noted, and thus the duodenum was radiographically divided into two portions for analysis, with duodenum 1 including the first two portions of the duodenum and duodenum 2 comprising the third and fourth portions of the duodenum. Mural visualization of stomach, duodenum, jejunum and ileum was graded on a scale of $0-3$, with 0 being no visualization, 1 being minimal, 2 being good and 3 being excellent visualization. Discrimination of the bowel wall from pancreas, cyst and lymph nodes was also ranked on $0-3$ scale, 0 being no, 1 being minimal, 2 being good visualization and 3 being excellent discrimination.

A questionnaire regarding oral contrast tolerability was provided to each patient after completion of CT. The patients were asked to rate the taste of the oral contrast material on a scale of $1-3$, with 1 being intolerable, 2 being unpleasant but tolerable, and 3 being pleasant. In addition, the patients were also asked whether they had any difficulties while ingesting the entire volume of contrast material and whether they disliked drinking whole milk or oral contrast material. Side effects including abdominal discomfort or cramping, nausea, vomiting, flatulence, and diarrhea were recorded. A cost comparison of the two agents was also performed.

\section{Statistical analysis}

Mean age differences between the milk and iopamiro groups were evaluated using the Student's unpaired $t$ test. Sex distribution was calculated and the differences were evaluated with the chi-square test. Degree of bowel distention and discrimination in the two study groups using the aforementioned 4-point scale was assessed by each reviewer, and the percentage of cases receiving each score was calculated. Percentages of cases with mural visualization in each study group were calculated and the chi-square test was used to examine the differences between the two groups. A $p$ value less than or equal to 0.05 was considered significant for all these statistical analyses.

\section{Results}

Among 110 patients receiving whole milk, 48\% were women and 52\% were men. Among 100 patients who received iodinated oral contrast, $45 \%$ were women and $55 \%$ were men. Patients who consumed milk were from 20-70 years (mean $50 \pm 14.2$ ) and those who ingested iodinated oral contrast were from 26-68 years (mean $52 \pm 15.8$ ). Statistically no significant difference was seen between two groups with respect to sex or age.

Table I shows statistically no significant difference between whole milk and iodinated oral contrast groups with respect to the degree of bowel distention in all segments of the bowel.

Table I: Qualitative analysis of gastrointestinal tract distention

\begin{tabular}{|c|c|c|c|}
\hline $\begin{array}{l}\text { Bowel } \\
\text { segment } \\
\text { distention } \\
\text { score }\end{array}$ & $\begin{array}{c}\text { Milk } \\
(\mathrm{n}=110)\end{array}$ & $\begin{array}{l}\text { Iodinated oral } \\
\text { contrast } \\
\text { medium } \\
(n=100)\end{array}$ & $\mathrm{p}$ \\
\hline \multicolumn{4}{|l|}{ Antrum } \\
\hline 0 & 1 & 1 & \multirow{4}{*}{0.811} \\
\hline 1 & 2 & 4 & \\
\hline 2 & 20 & 19 & \\
\hline 3 & 87 & 76 & \\
\hline \multicolumn{4}{|l|}{ Duodenum 1} \\
\hline 0 & 23 & 27 & \multirow{4}{*}{0.167} \\
\hline 1 & 27 & 20 & \\
\hline 2 & 45 & 47 & \\
\hline 3 & 5 & 6 & \\
\hline \multicolumn{4}{|l|}{ Duodenum 2} \\
\hline 1 & 47 & 40 & \multirow{2}{*}{0.488} \\
\hline 3 & 2 & 5 & \\
\hline \multicolumn{4}{|l|}{ Jejunum } \\
\hline 0 & 6 & 6 & \multirow{4}{*}{0.339} \\
\hline 1 & 28 & 18 & \\
\hline 2 & 70 & 65 & \\
\hline 3 & 6 & 11 & \\
\hline \multicolumn{4}{|l|}{ Ileum } \\
\hline 0 & 1 & 0 & \multirow{3}{*}{0.750} \\
\hline 1 & 26 & 27 & \\
\hline 3 & 3 & 3 & \\
\hline
\end{tabular}

Table II shows that significant difference was observed between whole milk and iodinated contrast groups in mural visualization of bowel segments. 
Table II: Qualitative analysis of gastrointestinal tract mural visualization

\begin{tabular}{|c|c|c|c|}
\hline $\begin{array}{l}\text { Bowel } \\
\text { segment mural } \\
\text { visualization } \\
\text { score }\end{array}$ & $\begin{array}{c}\text { Milk } \\
(\mathrm{N}=110)\end{array}$ & $\begin{array}{l}\text { Iodinated oral } \\
\text { contrast } \\
(\mathrm{N}=100)\end{array}$ & $\mathrm{p}$ \\
\hline Stomach & & & \multirow{5}{*}{0.001} \\
\hline 0 & 0 & 4 & \\
\hline 1 & 2 & 30 & \\
\hline 2 & 8 & 40 & \\
\hline 3 & 100 & 20 & \\
\hline \multicolumn{4}{|l|}{ Duodenum } \\
\hline 0 & 0 & 3 & \multirow{4}{*}{0.001} \\
\hline 1 & 1 & 35 & \\
\hline 2 & 8 & 58 & \\
\hline 3 & 101 & 4 & \\
\hline \multicolumn{4}{|l|}{ Jejunum } \\
\hline 0 & 2 & 8 & \multirow{4}{*}{0.001} \\
\hline 1 & 20 & 70 & \\
\hline 2 & 30 & 18 & \\
\hline 3 & 58 & 4 & \\
\hline \multicolumn{4}{|l|}{ Ileum } \\
\hline 0 & 2 & 8 & \multirow{4}{*}{0.001} \\
\hline 1 & 20 & 70 & \\
\hline 2 & 30 & 18 & \\
\hline 3 & 58 & 4 & \\
\hline
\end{tabular}

Table III shows the difference in bowel segment discrimination for milk and iodinated contrast medium. But no statistically significant difference was observed.

Table IV shows the tolerability results of patient for milk and iodinated contrast medium. Patients tolerated milk better.

Table V shows gastrointestinal symptoms following ingestion of whole milk and iodinated oral contrast medium.

\section{Cost Comparison}

The cost for milk is significantly less than the cost for Iopamiro per study. Specifically, milk costs 60 BDT per study versus 900 BDT per study for iopamiro.
Table III: Qualitative analysis of gastrointestinal tract discrimination

\begin{tabular}{|c|c|c|c|}
$\begin{array}{c}\text { Bowel segment } \\
\text { discrimination } \\
\text { score }\end{array}$ & Milk & $\begin{array}{c}\text { Iodinated oral } \\
\text { contrast medium }\end{array}$ & \\
$\begin{array}{c}\text { Pancreas- } \\
\text { duodenum } \\
\text { discrimination }\end{array}$ & $(\mathrm{n}=110)$ & $(\mathrm{n}=100)$ & \\
0 & 2 & & \\
1 & 5 & 3 & 0.709 \\
3 & 80 & 75 & \\
\hline $\begin{array}{c}\text { As opposed } \\
\text { to cysts }\end{array}$ & $(\mathrm{n}=21)$ & $(\mathrm{n}=19)$ & \\
0 & 2 & 0 & \\
1 & 3 & 1 & 0.264 \\
2 & 6 & 4 & \\
3 & 10 & 14 & \\
\hline $\begin{array}{c}\text { As opposed to } \\
\text { lymph nodes }\end{array}$ & $(\mathrm{n}=49)$ & $(\mathrm{n}=56)$ & \\
0 & 2 & 1 & \\
1 & 5 & 3 & 0.655 \\
2 & 12 & 35 & \\
3 & 30 & & \\
\hline
\end{tabular}

Table IV: Comparison of tolerability results of milk and iodinated contrast medium

\begin{tabular}{|c|c|c|c|}
\hline Variable rated & $\begin{array}{c}\text { Milk } \\
(\mathrm{n}=110)\end{array}$ & $\begin{array}{c}\text { Iodinated oral } \\
\text { contrast medium } \\
(\mathrm{n}=100)\end{array}$ & $\mathrm{p}$ \\
\hline $\begin{array}{c}\text { Test score } \\
1\end{array}$ & 5 & 70 & \\
2 & 15 & 25 & 0.001 \\
3 & 90 & 5 & \\
$\begin{array}{l}\text { Difficulty in } \\
\text { consuming } \\
\text { entire volume }\end{array}$ & 6 & 12 & 0.091 \\
\hline $\begin{array}{l}\text { Aversion to oral } \\
\text { contrast material }\end{array}$ & 5 & & \\
\hline
\end{tabular}

Table V: Gastrointestinal symptoms

\begin{tabular}{|l|c|c|c|}
\hline Symptoms & $\begin{array}{c}\text { Milk } \\
(\mathrm{n}=110)\end{array}$ & $\begin{array}{c}\text { Iodinated oral } \\
\text { contrast medium } \\
(\mathrm{n}=100)\end{array}$ & $\mathrm{p}$ \\
\hline $\begin{array}{l}\text { Abdominal } \\
\text { discomfort }\end{array}$ & 4 & 10 & 0.065 \\
$\begin{array}{l}\text { Abdominal } \\
\text { cramps }\end{array}$ & 3 & 5 & 0.309 \\
$\begin{array}{l}\text { Nausea } \\
\text { Vomiting }\end{array}$ & 4 & 20 & 0.001 \\
\hline Flatulence & 1 & 10 & 0.003 \\
\hline Diarrhea & 3 & 07 & 0.579 \\
\hline & & 1 & 0.347 \\
\hline
\end{tabular}




\section{Discussion}

The increasing use of multidetector computed tomography (MDCT) and the rising popularity of volume imaging have renewed a need for efficacious low-attenuation oral contrast agents because traditional high-attenuation contrast agents interfere with image processing techniques. Low-attenuation agents have been shown to be valuable in the diagnosis of small-bowel disorders such as ischemia $^{15}$, neoplasm ${ }^{16}$, and Crohn's disease. ${ }^{17-19}$ Such agents have also been proven to be valuable in gastric and duodenal demarcation for the evaluation of pancreatic and biliary abnormalities. ${ }^{20}$ Various low-attenuation oral contrast agents have been explored for use with abdominal $\mathrm{CT}^{21}{ }^{21}$ Among these agents, whole milk has been shown to compare favorably with traditional positive oral contrast material in gastrointestinal tract distention and mural visualization. ${ }^{5,12}$ Our study focused on comparing the two agents with respect to effectiveness in bowel distention and mural visualization, patient acceptance, and cost.

We found statistically no significant differences between whole milk and iopamiro with respect to degree of bowel distention among all segments of visualization, but whole milk had better patient acceptance, fewer abdominal symptoms, and lower cost than iopamiro. With rising medical costs and an increasing volume of CT examinations performed for the evaluation of gastrointestinal abnormalities, an oral contrast agent that enables effective gastrointestinal tract evaluation while minimizing cost is ideal, and whole milk patient satisfaction and willingness to ingest milk may lead to higher patient compliance while undergoing CT examinations, which may lead to earlier detection and treatment of diseases.

Whole milk showed excellent antral distention compared with the small bowel. This phenomenon is probably because a portion of the oral contrast material was consumed immediately before scanning and it did not have sufficient time to exit the stomach. This situation is ideal for and is often used in pancreatic and biliary studies. ${ }^{20}$ The slightly decreased distention in the distal duodenum is likely secondary to peristalsis propelling the contrast material that was administered 45-60 minutes before scanning into the distal small bowel, whereas the contrast material administered immediately before scanning had not yet reached the distal duodenum. Distention of the duodenum, especially the third portion, is further compromised by its anatomic situation between solid organs and vascular structures. Similar to the distention results, visualization of the antral, jejunal, and ileal walls was slightly better than visualization of the duodenal wall. The visualization results paralleling the distention data support the general observation that better bowel distention imparts better bowel wall visualization.

Intravenous (IV) glucagon was not used in either the milk or the iopamiro group, yet good gastrointestinal tract distention was achieved. Such a phenomenon is expected for milk because the fat contained in milk effectively slows peristalsis, resulting in superb distention. The elimination of pharmacologic effects of IV glucagon, such as inhibition of gastric emptying, is beneficial to patients in many respects. In the study performed by Winter et al, the combination of water and glucagon was associated with nausea and emesis in $14 \%$ and $7 \%$ of patients, respectively. ${ }^{6}$ Although it is uncertain whether these symptoms were due to the use of glucagon, the ionic IV contrast material, or a combination of the two, such adverse reactions increase patient discomfort and the risk of aspiration. In addition, the ability to forgo IV glucagon administration will reduce costs.

The results of our study show that whole milk is comparable for bowel distention to iopamiro and better in mural visualization. In the setting of better patient acceptance, fewer gastrointestinal symptoms after consumption, and lower cost, whole milk proves to be a cost-effective alternative to iopamiro as a low-attenuation oral contrast agent. The ability of this inexpensive medium to produce adequate bowel wall visualization provides considerable potential for further cost-effective applications of volume imaging with MDCT.

\section{References}

1. Churchill RJ, Reynes CJ, Love L, Moncada R. CT imaging of the abdomen: methodology and normal anatomy. Radiol Clin North Am 1979; 17: 13-24. 
2. Nyman U, Dinnetz G, Anderson I. E-Z-CAT: an oral contrast medium for use in computed tomography of the abdomen. Acta Radiol Diagn (Stockh) 1984; 25: 121-124.

3. Garrett PR, Meshkov SL, Perlmutter GS. Oral contrast agents in CT of the abdomen. Radiology 1984; 153: 545-546.

4. Raptopoulos V. Technical principles in CT evaluation of the gut. Radiol Clin North Am 1989; 27: 631-651.

5. Thompson SE, Raptopoulos V, Sheiman RL, McNicholas MJ, Prassopulos P. Abdominal helical CT: milk as a lowattenuation oral contrast agent. Radiology 1999; 211: 870-875.

6. Winter TC, Ager JD, Nghiem HV, Hill RS, Harrison S, Freeny P. Upper gastrointestinal tract and abdomen: water as an orally administered contrast agent for helical CT. Radiology 1996; 201: 365-370.

7. Raptopoulos V, Davis MA, Davidoff A, Karellas A, Hays D, D’Orsi CJ. Fat-density oral contrast agent for abdominal CT. Radiology 1987; 164: 653-656.

8. Sahani DV, Jhaveri KS, D'souza RV, Varghese JC, Halpern E, Harisinghani MG. Evaluation of simethiconecoated cellulose as a negative oral contrast agent for abdominal CT. Acad Radiol 2003; 10: 491-496.

9. Ramsay DW, Markham DH, Morgan B, Rodgers PM, Liddicoat AJ. The use of dilute calogen as a fat density oral contrast medium in upper abdominal computed tomography, compared with the use of water and positive oral contrast media. Clin Radiol 2001; 56: 670-673.

10. Friedrich JM, Skinningsrud K, Welter C, Eide H, Merkle E. Oral administration of iopentol (Imagopaque $300 \mathrm{mg}$ $\mathrm{I} / \mathrm{ml}$ ) compared with amidotrizoate (Peritrast $300 \mathrm{mg}$ $\mathrm{I} / \mathrm{ml})$, both diluted to $2 \%(\mathrm{v} / \mathrm{v})$, in imaging of the gastrointestinal tract in abdominal contrast enhanced CT: a clinical trial assessing patient tolerance, distribution of contrast medium and Hounsfield unit measurements. Eur Radiol 1997; 7[Suppl 4]: S140-S144.

11. Megibow AJ, Babb JS, Hecht EM, Cho JJ, Houston C, Boruch MM. Evaluation of bowel distention and bowel wall appearance by using neutral oral contrast agent for multidetector row CT. Radiology 2006; 236: 87-95.
12. Megibow AJ, Zerhouni EA, Hulnick DH, Beranbaum ER, Balthazar EJ. Air insufflation of the colon as an adjunct to computed tomography of the pelvis. J Comput Assist Tomogr 1984; 8: 797-800.

13. Raptopoulos V, Davis MA, Smith EH. Imaging of the bowel wall: computed tomography and fat density oralcontrast agent in an animal model. Invest Radiol 1986; 21: 847-850.

14. Hebert JJ, Taylor AJ, Winter TC, Reichelderfer M, Weichert JP. Low-attenuation oral GI contrast agents in abdominal-pelvic computed tomography. Abdom Imaging 2006; 31: 48-53.

15. Horton KM, Fishman EK. Multi-detector row CT of mesenteric ischemia: can it be done? RadioGraphics 2001; 21: 1463-1473.

16. Horton KM, Fishman EK. Multidetector-row computed tomography and 3-dimensional computed tomography imaging of small bowel neoplasms: current concept in diagnosis. J Comput Assist Tomogr 2004; 28: 106-116.

17. Turetschek K, Schober E, Wunderbaldinger P, Bernhard C, Sehima W, Puespock A. Findings at helical CTenteroclysis in symptomatic patients with Crohn's disease: correlation with endoscopic and surgical findings. J Comput Assist Tomogr 2002; 2: 488-492

18. Wold PB, Fletcher JG, Johnson CD, Sandborn WJ. Assessment of small bowel Crohn's disease: noninvasive peroral CT enterography compared with other imaging methods and endoscopy-feasibility study. Radiology 2003; 229: 275-281.

19. Reittner P, Goritschnig T, Petritsch W, Doerfler O, Preidler KW, Hinterleitner T. Multiplanar spiral CT enterography in patients with Crohn's disease using a negative oral contrast material: initial results of a noninvasive imaging approach. Eur Radiol 2002; 12: 2253-2257.

20. Winter TC, Freeny PC, Nghiem HV. Extrapancreatic gastrinoma localization: value of arterial phase helical CT with water as an oral contrast agent. AJR 1996; 166: 51-52.

21. Balthazar EJ, Megibow AJ, Hulnick DH, Naidich DP. Carcinoma of the colon: detection and preoperative staging by CT. AJR 1988; 150: 301-306. 